\title{
Política linguística para as línguas oficiais em Timor-Leste: o português e o Tétum-Praça
}

Davi Borges de Albuquerque (UnB) Kerry Taylor-Leech (Leitora em Linguística Aplicada - Griffith University)(UFS)

\section{Resumo}

O presente artigo tem como objetivo analisar a politica e o planejamento linguísticos para o português e o Tétum-Praça em Timor-Leste, já que ambas as linguas são asseguradas pela constituição do país, que data de 2002, como línguas oficiais. Desta forma, em (2), serão discutidos o alçamento do status e do corpus do Tétum-Praça; em (3), será examinada principalmente a questão do status da lingua portuguesa em território leste-timorense; e, em (4), serão elaboradas grades de análise para avaliar a eficácia do planejamento linguístico leste-timorense em diferentes momentos de sua história.

Palavras-chave: política linguística; planejamento linguístico; linguas oficiais; Timor-Leste; lingua portuguesa. 


\section{Introdução}

A República Democrática de Timor-Leste é um território de uma pequena ilha localizada no extremo sudeste asiático e próximo ao norte da Austrália. Ainda, a parte oeste da ilha pertence à Indonésia, assim é o único país que Timor-Leste faz fronteira física. O país conquistou sua independência recentemente no ano de 2002, após uma dominação indonésia, marcada por extrema opressão e violência, que se iniciou em 1975 e terminou em 1999. Durante o período de 1999 até 2002, o país esteve na administração provisória da ONU (Organizações das Nações Unidas) com a missão intitulada de UNTAET (United Nations Transitional Administration in East Timor).

A constituição do ano de 2002 elegeu a língua portuguesa e a língua Tétum (na variedade chamada de Tétum-Praça') como línguas oficiais de Timor Leste, ainda são aceitas a língua inglesa e o indonésio como línguas de trabalho. Seguem os artigos da Constituição da República Democrática de Timor-Leste:

\section{Artigo 13. ${ }^{\circ}$ (Línguas oficiais e línguas nacionais)}

1. O tétum e o português são as línguas oficiais da República Democrática de Timor-Leste.

2. O tétum e as outras línguas nacionais são valorizadas e desenvolvidas pelo Estado. (...)

\section{Artigo 159. (Línguas de trabalho)}

A língua indonésia e a inglesa são línguas de trabalho em uso na administração pública a par das línguas oficiais, enquanto tal se mostrar necessário (REPÚBLICA DEMOCRÁTICA DE TIMOR-LESTE, 2002, p. 11-12/45).

\footnotetext{
1 Na bibliografia linguística, há diferentes grafias para o nome Tétum. O presente autor emprega com maior frequência o termo Tetun Prasa, já que este segue a ortografia oficial da língua. No entanto é possível encontrar também Tetum Praça e Teto Praça. Neste artigo, optei por empregar o termo Tétum-Praça pelo fato de ser o termo usado na constituição.
}

Sobre as demais línguas nativas leste-timorenses, além do Artigo $13^{\circ}$ da constituição, que decreta que "as línguas nacionais são valorizadas e desenvolvidas pelo Estado", há informações somente no Decreto do Governo n ${ }^{\circ}$. 1.2004 de 14 de abril, intitulado O padrão ortográfico da língua Tétum, que regula o Tétum-Oficial e o papel do INL (Instituto Nacional de Linguística). Neste decreto, há somente duas alíneas no Artigo $4{ }^{\circ}$ que dizem o seguinte:

1. O INL deve desenvolver as actividades científicas necessárias à preservação e protecção das restantes línguas nacionais, trabalhando nomeadamente os respectivos padrões ortográficos. 
2. O trabalho de pesquisa e desenvolvimento do Tétum e restantes línguas nacionais da República Democrática de Timor-Leste deve ser conduzido em estreita cooperação com o INL (REPÚBLICA DEMOCRÁTICA DE TIMOR-LESTE, 2004, p. 2).

Desta maneira, no presente artigo serão analisados a política e o planejamento linguísticos de Timor-Leste a respeito das línguas oficiais do país, a saber: o português e o Tétum, que além de ser língua oficial é considerada língua nacional, conforme foi apresentado acima. Serão verificados também aspectos das políticas linguísticas anteriores, e como se encontra o estado atual do planejamento linguístico leste-timorense, observando-se características de como foi alterada a ecologia das línguas em Timor-Leste. Para tanto, em (2), serão discutidos o alçamento do status e do corpus do Tétum-Praça; em (3), será avaliada principalmente a questão do status da língua portuguesa em território leste-timorense; e, em (4), será elaborada uma proposta tipológica para a política linguística leste-timorense.

Vale lembrar que a língua inglesa e o indonésio também possuem um papel importante na ecologia linguística atual em Timor-Leste, conforme será apenas mencionado na seção (4). Porém, uma análise específica da política e planejamentos linguísticos envolvendo essas línguas em território leste-timorense, assim como o impacto delas na ecologia nativa, foge do escopo deste artigo, focado nas línguas oficiais, e será reservada para um trabalho futuro.

Mapa 1: Timor Leste e suas fronteiras

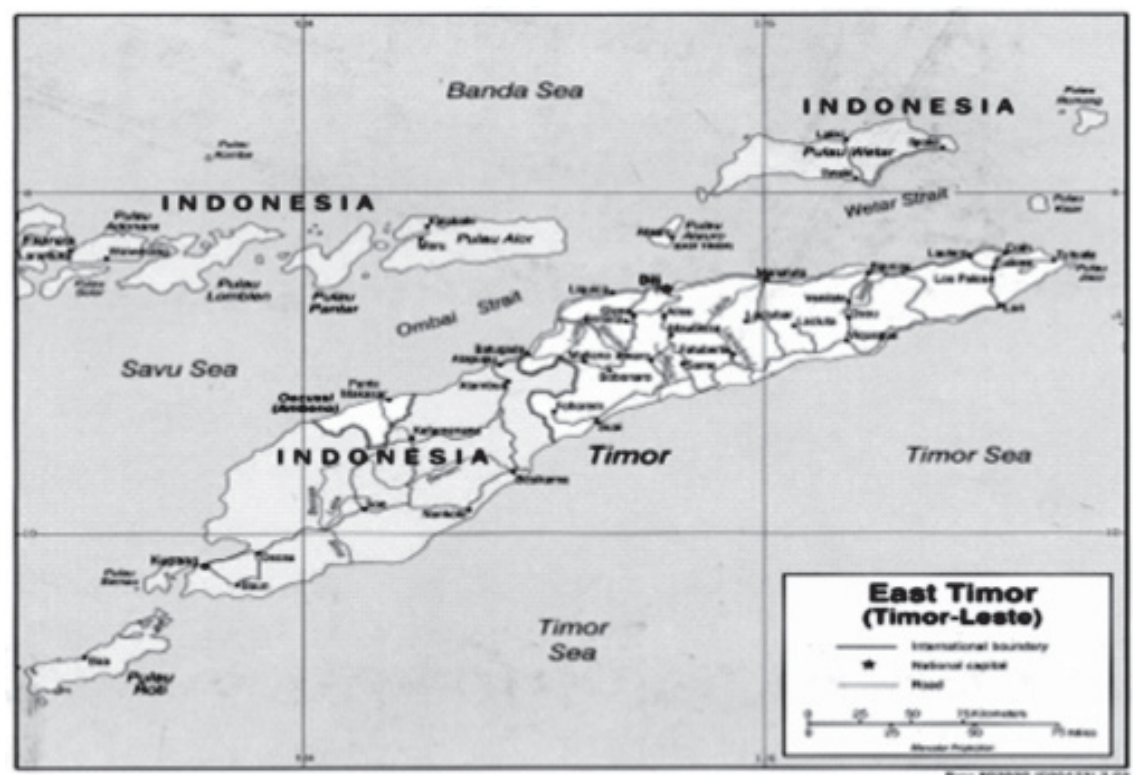

(Fonte: http://www.lib.utexas.edu/maps/middle_east_and_asia/east_timor_pol_03.pdf) 


\section{A modificação do status e do corpus para o Tétum-Praça}

Nesta seção serão analisados os contextos sócio históricos em que a língua Tétum ascendeu seu status de maneira in vivo, seguidos pelas modificações de status in vitro. Em seguida, serão apresentadas como foram feitas as alterações do corpus da língua Tétum, que foram elaboradas por planejamentos linguísticos específicos, ou seja, em situação in vitro. O status da língua portuguesa em Timor-Leste será discutido na seção seguinte.

Digno de nota é que a distinção de planejamento de status e planejamento de corpus, proposta elaborada por Kloss (1969) e desenvolvida por Calvet (1996), que defini status como a posição e funções de uma língua dentro de sua comunidade e corpus como o sistema linguístico, assim 'planejamento de status' são ações sobre a função da língua e as relações desta com as demais línguas e 'planejamento de corpus' são as ações sobre a forma da língua.

Antes de ser iniciada a análise desta seção, serão apontados alguns pressupostos teóricos adotados pelo presente autor. Neste trabalho, entende-se 'política linguística' como um conjunto das decisões em relação à língua diante da sociedade, e o 'planejamento linguístico' (fr. planification linguistique) é a aplicação das decisões da política linguística (CALVET, 1996). Esta distinção entre o conjunto de decisões políticas e a implantação delas, proposta por Calvet, também foi compartilhada por Boyer (1996) que inseriu outro conceito importante para o estudo das relações entre língua, política e sociedade ao considerar que algumas ações sociais são capazes de interferir no planejamento linguístico ou em outros campos de atuação da linguística a nível social, sendo de certa forma 'políticas não linguísticas'. Posteriormente, Blanchet (2000) desenvolveu este conceito para sua teoria de 'linguística de campo' (fr. linguistique du terrain), que grosso modo equivale a distinção do in vivo, práticas sociais naturais em relação à língua e seu desenvolvimento dentro de uma sociedade, e in vitro, construções políticas e artificiais para planejar a língua, proposta inicialmente por Calvet (1993) e aperfeiçoada pelo mesmo autor em Calvet $(1996,1997)$.

A língua Tétum formou-se por volta do século XIII a partir de um ancestral de origem austronésia, chamado de Proto Timórico (HULL, 2001). Os primeiros contatos com o colonizador europeu aconteceram no início do século XVI, que já encontraram um número alto de línguas nativas na parte leste da ilha de Timor, na época colônia portuguesa. Desta maneira, os diferentes grupos etnolinguísticos já utilizavam uma língua franca para se comunicar entre eles, que era a língua Tétum. Fox (2000) considera as origens da língua Tétum como língua franca, ou língua veicular, um tanto obscuras, porém Thomaz (2002), ao realizar estudos históricos e linguísticos, considera que a língua Tétum 
vem sendo usada como língua franca em Timor-Leste desde um período anterior ao século XVII, e Albuquerque (2009), ao analisar o histórico do contato de línguas em Timor, afirma que a data provável seja o século XV.

Ainda, a língua Tétum possui duas variedades principais, conhecidas como Tétum-Praça, usada como língua franca e L1 dos habitantes da capital (distrito de Dili), e Tétum-Térik, variedade rural que conservou certas estruturas arcaizantes e é L1 de diferentes comunidades mais isoladas, principalmente nos distritos de Viqueque, a leste, e Suai e Bobonaro, a oeste, próximo à fronteira com a Indonésia. Assim, além de ser usada em grande maioria do país como língua franca, de acordo com diferentes censos sua taxa de veicularidade está entre $80 \%$ e $90 \%$ da população, o Tétum é L1 de diferentes comunidades, alcançando cerca de $24-30 \%$ de falantes L1 somadas as duas variedades, sendo também falada em território indonésio, próximo à fronteira leste-timorense, principalmente em Atambua².

De acordo com o que foi apresentado anteriormente, podese afirmar que o Tétum alcançou o status de língua veicular (língua franca), língua de grupo e língua nacional de maneira in vivo através de processos sociais e históricos, que envolveram migrações de populações, rotas comerciais pelo sudeste asiático, e guerras e dominações entre grupos etnolinguísticos nativos ${ }^{3}$, entre os acontecimentos históricos que se destacaram foi à expansão de um reino falante de Tétum, o reino de Wehale, que dominou grande parte do território leste-timorense, chamada de 'província dos Belos', e impôs sua língua aos dominados (THOMAZ, 2002).

De maneira diferente, a língua Tétum foi alçada ao status de língua de religião por um processo in vivo recente: a dominação indonésia. Indonésia invadiu Timor Português, nome como era chamado antigamente, em 1975 e dominou o país até 1999.

2 Dados extraídos de National Board of Statistics (2006) e Programa das Nações Unidas para o Desenvolvimento (2002). Taylor-Leech (2009, p.14) apresenta números semelhantes, apenas com ligeiras modificações, mas que também possuem validade, já que os recenseamentos em Timor-Leste apresentam certas discrepâncias uns com os outros em relação a alguns números.

3 Para informações maiores a respeito das relações entre sociedade, história e línguas em Timor-Leste, ver Fox (2000), Hull (2001), Thomaz (2002) e Albuquerque (2009).
A política de dominação indonésia, segundo testemunhos dos próprios padres leste-timorenses em Costa (2002/2003), a igreja católica, que é a religião predominante, e seus externatos, que eram as únicas instituições de ensino ao lado de escolas militares, foram desde o início da invasão indonésia vigiada pelos militares. Posteriormente, houve um telegrama oficial da Indonésia que decretava a eliminação de tudo que tivesse berbau portugis 'sabor português', principalmente na educação e cultura dos cidadãos leste-timorenses (COSTA, 2002/2003). Assim, os párocos iniciaram traduções dos textos litúrgicos de português para Tétum como única alternativa para continuarem o culto católico, tornando a língua Tétum como língua de religião até a atualidade.

Em 1999, o país livrou-se da dominação indonésia e foi governado até o ano de 2002, quando finalmente tornou-se independente, por uma junta chamada de UNTAET (United Nations Transitional Administration in East Timor). Durante o período de 1999-2002, o CNRT (Conselho Nacional da Resistência Timorense) 
se reuniu e procurou discutir as diretrizes que o novo país seguiria. Em relação à política linguística decidiu considerar todas as línguas nativas como 'línguas nacionais', incluindo entre elas o Tétum, conforme foi citado no início deste artigo, porém não as enumerou no documento governamental, permanecendo até a atualidade problemas a respeito do reconhecimento e diferenciação entre línguas e variedades. O planejamento linguístico que teve maior impacto sobre o Tétum foi o de alçá-lo ao status de língua oficial, utilizando argumentos como: a veicularidade, a maior parte da população fala o Tétum e o emprega na comunicação; o símbolo de resistência à Indonésia; o passado glorioso de sobrevivência ao regime português e heróis míticos ligados a esta sobrevivência; a identidade nacional, pois a língua Tétum acaba por diferenciar o povo leste-timorense dos países vizinhos.

Esse planejamento linguístico acabou por, além de alterar o status do Tétum, fazer modificações no corpus. Ainda, todas as mudanças foram elaboradas artificialmente, sendo consideradas in vitro. O órgão responsável para regular a alteração no corpus do Tétum foi o INL (Instituto Nacional de Linguística) cuja primeira tarefa foi escolher uma variedade e padronizar a ortografia. A variedade selecionada foi o Tétum-Praça falada em Dili, capital de Timor-Leste, e a ortografia foi padronizada após uma análise histórica das diferentes propostas ortográficas existentes para a língua e publicada pela instituição em INL (2002). A modificação seguinte foi efetuada no léxico da língua, já que todo o vocabulário moderno (informática, jurídico-administrativo, político, científico, tecnológico etc.) e a terminologia científica estavam ausentes. A solução encontrada foi recorrer aos empréstimos, em sua maioria de origem portuguesa, conforme o Matadalan Ortográfiku ba Tetun-Prasa (INL, 2003) que enumerou cerca de 30.000 lexemas dos campos semânticos mais variados.

\section{O status da língua portuguesa}

Conforme foi apontado anteriormente, o colonizador português chegou à ilha de Timor no início do século XVI, porém esta não despertou muito interesse até meados do século XVIII, quando comparadas às ilhas vizinhas, como Solor e Flores (FIGUEIREDO, 2004, p. 113). A educação, durante esse período, ficou a cargo dos frades dominicanos, que possuíam o objetivo de catequizar, além do ensino formal, e também acabavam por selecionar a maioria dos alunos a ser ensinados, sendo esta seleção preocupada em admitir nas escolas dominicanas somente os cidadãos nativos mais influentes, como: nobres e suas respectivas famílias, chefes de vilarejo, entre outros (HAJEK, 2000).

Toda a documentação, ou outras fontes, era de responsabilidade de funcionários da coroa portuguesa que se reportavam ao Estado da Índia, superintendência que gerenciava a capitania de Solor-Timor (FIGUEIREDO, 2004) e, consequentemente, eram 
redigidas exclusivamente em língua portuguesa. Vale lembrar que os alunos das escolas dominicanas em Timor Português, e que exerceriam futuros cargos administrativos na ilha a favor da coroa portuguesa, eram encorajados a continuar seus estudos avançados em Macau ou Goa, principalmente em relação à língua portuguesa.

Assim, o número de portugueses em Timor sempre foi baixo, ficando em torno de cem até meados do século XIX, segundo pode ser constatado em documentações existentes em Sá (1961) e Boxer (1947). Este fato é importante, pois acaba por explicar o motivo do número de leste-timorenses falantes de língua portuguesa ter se mantido baixo até a década de 1970.

Somente com modificações que ocorreram nos séculos XVIII e XIX, o sistema de educação formal foi alterado em Timor, principalmente com as reformas pombalinas, que marcaram a transição do absolutismo para o liberalismo, e as instituições eclesiásticas deveriam primeiramente reportar-se ao Estado. Assim, foi alterada toda a estrutura do ensino formal, em 1879, com os seguintes documentos, que foram publicados no ano seguinte: Primeiro Relatório Apresentado à Comissão de Missões do Ultramar e Segundo Relatório Apresentado à Comissão de Missões do Ultramar. O primeiro tornava as atividades da igreja no Ultramar como subserviente ao Estado, enquanto o segundo regulava as atividades do Colégio das Missões Ultramarinas, assim como procurava resolver certos problemas, como: o número reduzido de alunos (cerca de 50) e de missionários formados anualmente (entre 6 e 7), e o ensino e estudo das línguas da região (FIGUEIREDO, 2004, p. 391).

Ainda, o Segundo Relatório Apresentado à Comissão de Missões do Ultramar afirmou que o ensino e o estudo científico das línguas nativas podem proporcionar uma aproximação maior com o povo, assim como facilitar a difusão escolar, porém o Estado deveria promover em larga escala apenas o ensino da língua portuguesa como ferramenta de assimilação social e política (CORDEIRO, s.d., p. 137).

O segundo marco para a escolarização e a retomada do ensino de língua portuguesa foi em Timor Português a fundação do Colégio de Soibada, em 1898 (THOMAZ, 2002). Ainda, segundo Thomaz (2002), o autor informa que nos anos anteriores à invasão indonésia ocorreu aumento significativo na população falante e alfabetizada em língua portuguesa: em 1970-1971 o número de crianças em idade escolar frequentando as escolas era de $28 \%$; já em 1972-1973 esse número subiu para 51\%; e em 1973-1974, anos anteriores à invasão, o número aumentou para 77\%. Em Thomaz (1994), há uma análise das estatísticas oficiais portuguesa da época que, segundo cálculos elaborados pelo autor, a parcela da população que falava a língua portuguesa no período anterior à invasão indonésia, no início da década de 1970, era em torno de $15 \%$ da população. Os números apresentados anteriormente, assim 
como os cálculos feitos pelo autor foram elaborados com base em documentos e relatórios da administração portuguesa da época.

Assim, conforme os dados históricos apresentados acima, o status da língua portuguesa manteve-se alto durante todo o período e com seu corpus diminuindo ligeiramente e mantendo-se baixo. Esse domínio do status da língua portuguesa, como a língua do colonizador, foi somente alterado devido à dominação indonésia, que se iniciou em 1975 e se estendeu até 1999. Neste período, Timor Timur, como passou a ser chamada pelos indonésios a parte leste da ilha de Timor, sofreu uma reviravolta no planejamento linguístico, ficando submetido, como país dominado, às decisões da Indonésia.

A Indonésia anexou Timor como sua $27^{\mathrm{a}}$ província e impôs a língua indonésia a toda a população leste-timorense, utilizando-se das seguintes estratégias: completa reforma no ensino, eliminando a língua portuguesa e diminuindo o valor e importância do Tétum-Praça; havia fluxo constante de materiais didáticos em indonésio; professores e demais profissionais capacitados também foram enviados a Timor; a língua usada na administração, na escola, no comércio e meios de comunicação passou a ser o indonésio. Essas estratégias acabaram por formar toda uma geração de cidadãos leste-timorense sob a cultura indonésia, o que torna o processo de escolarização e inserção no mercado de trabalho atual um tanto problemático.

A língua portuguesa voltou a retomar seu status somente em tempos recentes, em 2002, com sua garantia de língua oficial na constituição. Contudo vários problemas persistem até os dias de hoje, sendo os principais: o corpus do português, ou seja, o conjunto de suas práticas linguísticas retirei a", permanece extremamente reduzido; o status foi retomado parcialmente, já que retirei 'a' o Tétum-Praça também funciona como língua oficial e passa a assumir várias funções; e, ao aceitar o inglês e o indonésio como línguas de trabalho, a língua portuguesa passa a ter competição em alguns setores da sociedade e em seus respectivos usos.

\section{Aplicação de uma tipologia da política linguística em Timor-Leste}

Calvet (1993) afirma que somente uma definição sociolinguística da língua é apropriada para os estudos de política linguística. Desta forma, a dicotomia de status e corpus não é suficiente para descrever a realidade da língua dentro de uma sociedade. Por isso, certos conceitos desenvolvidos para a sociolinguística serviram como instrumentos de análise para a política linguística. Foi para superar tal condição que Chaudenson (1991) elaborou sua 'grade de análise' (fr. grille d'analyse), levando em conta diversas situações sociais e multilíngues que podem afetar a análise, assim como reformulou a dicotomia status e corpus (eixos centrais em sua grade de análise) com o corpus referindo-se a todo o conjunto 
de práticas linguísticas e o status sendo de grande importância, já que passa a ser as representações da língua dentro da sociedade.

Inicialmente, essa análise desenvolvida por Chaudenson (1991) foi aplicada para descrever as funções e os usos da língua francesa nas situações multilíngues dos países francófonos. Daí, a classificação de Calvet (1996) para esse modelo de análise de Chaudenson como 'tipologia de situações plurilíngues' (fr. typologies de situations plurilingues).

A grade de análise de Chaudenson também pode ser utilizada de maneira inversa, ou seja, ao invés de relacionar uma língua com vários países (o francês e os países francófonos), ela pode ser usada para relacionar as várias línguas com o país onde estas são faladas. Este é o procedimento de análise que será realizado nesta seção, serão elaboradas diferentes grades de análise, contrastando o português e o Tétum-Praça, com os objetivos de: relacionar a diferença entre status e corpus de ambas as línguas; servir como uma ferramenta expositiva que visa resumir as informações a respeito do planejamento linguístico apresentadas nas seções anteriores, em (2) e (3); ser uma base para a avaliação do funcionamento do planejamento linguístico em Timor-Leste,

4 Os valores numéricos para o status e o corpus foram atribuídos de acordo com a proposta de Chaudenson (2004), que procurou diminuir a arbitrariedade desses valores, apresentando critérios mais detalhados para a numeração.

5 Ainda, seguindo os atributos de Fasold (1984), há alguns casos em que a análise não ocorre de maneira binária, $(+)$ ou $(-)$, mas de forma ternária $(+),(-)$ e $(+/-)$, de acordo com a necessidade de se aproximar da descrição da realidade. Como exemplo a língua portuguesa, em relação a certos atributos há a seguinte enumeração: relacionada a um passado glorioso $(+$ / -), considerada pelos falantes como instrumento de unificação e diferenciação (+ / -). Estes atributos foram considerados como $(+$ / -) pelo fato de não ser amplamente aceito pela população, existindo certa controvérsia a respeito, ou seja, não poderia ser marcado $(+)$ nem $(-)$, pois se estaria desconsiderando segmentos da população e, assim, distanciando a análise da realidade do país. verificando se este está realmente coerente com a realidade dos falantes; acompanhar as mudanças diacrônicas do português e do Tétum-Praça no decorrer dos processos sócio-históricos que marcaram o país, como a invasão indonésia (1975-1999) e a recente independência (2002).

As grades de análise, segundo Chaudenson (1991), são organizadas no plano cartesiano nos eixos das abscissas $(x)$ e coordenadas (y), enumerados de 0 a 100. O eixo x (vertical) corresponde ao status e o eixo y (horizontal) ao corpus. A numeração aplicada (de 0 a 100) recebe algumas críticas por ser um tanto arbitrária, porém há uma série de fatores que serve como base para a atribuição dos valores numéricos, são eles: oficialidade, usos institucionais, usos na educação, utilização nos meios de comunicação e o emprego nos setores secundário e terciário, para o status; apropriação linguística, veicularidade e vernacularidade, tipos de competência e a produção linguística, para o corpus.

Ainda, Calvet (1996) acaba por somar outras situações que podem ajudar a atribuir valores de maneira mais sistemática, são elas: considerar fatores conflituais entre as línguas, o número de falantes, dados diacrônicos em geral e a funcionalidade da língua fora do país. Outra característica também utilizada aqui para se atribuir valores foram os atributos de Fasold (1984), que analisa se a língua é: oficial, nacional, grupal, veicular, internacional, escolar e religiosa ${ }^{4}$.

Dessa forma, foram atribuídos os valores numéricos ao status e corpus do português e do Tétum-Praça, seguindo apenas o preenchimento ou não (sistema binário) de todos os atributos mencionados acima ${ }^{5}$, conforme o exemplo: língua portuguesa 
$>$ oficial $(+)$, usada na educação $(+)$, língua veicular (-), língua vernácula $(-)^{6}$.

Para se verificar como evoluiu os efeitos do planejamento linguístico para as línguas português e Tétum, foi decidido realizar a grade de análise para três períodos distintos: Timor Português (até 1974), nome dado à colônia portuguesa; dominação indonésia, período que se estendeu de 1975, quando indonésia invadiu Timor Português, até 1999; Timor-Leste, que corresponde ao nome da nação (República Democrática de Timor-Leste) que obteve sua independência no ano de 2002.

\subsection{O período do Timor Português}

Os portugueses chegaram a Timor no início do século XVI e em meados deste mesmo século estabeleceram o ensino formal através de seminários dirigidos pelos padres dominicanos. Os padres objetivavam ensinar a gramática das línguas portuguesa e latina, e para a catequização dos cidadãos leste-timorenses utilizaram também a língua Tétum, já constatada desde os primeiros documentos coloniais como língua falada por grande parte da população nativa, como exemplo Sá (1961) e Castro (1996 [1943]) listam documentos, juntamente com o nome de uma série de nomes de diferentes povos/línguas, apontando a predominância do Tétum.

O ensino foi responsabilidade dos dominicanos até início do século XVIII, quando houve a reforma pombalina, que colocou os frades sob a égide do Estado, alterando comportamento, objetivo e conteúdos a ser ensinados. Houve também uma redução no número de escolas, que aumentaram somente no final do século seguinte, com as escolas oficias que se concentraram principalmente na capital, Dili (FIGUEIREDO, 2004).

Dessa maneira, o português em período anterior à invasão indonésia, era a língua da administração oficial, da instrução, do comércio e da religião, era também a língua usada para a comunicação com estrangeiros vindos de outras possessões portuguesas, principalmente Goa e Macau, e empregada nas comunicações, que eram basicamente relatórios e cartas. Assim, conclui-se que o português possuía um status alto (80) e em contrapartida um corpus baixo (20), já que era falado somente por uma pequena parcela da população, não era língua vernácula de nenhum cidadão timorense, não era utilizada nas comunicações informais e não possuía nenhum tipo de veicularidade.

De maneira diferente, o Tétum era falado por aproxima-

6 Segundo Calvet (1996) e Fasold (1984), língua veicular pode ser definida como a usada para comunicação interétnica, e língua vernácula é uma língua de comunidades específicas e que não estão representadas nas políticas oficiais. damente 90.000 pessoas como língua materna (MARCOS, 1995), cerca de $15 \%$ da população na década de 1970, além de funcionar como língua veicular por todo o território, conforme foi exposto anteriormente, e ser usada na fronteira com a indonésia. Ainda, o Tétum está vinculado a um passado glorioso e é um elemento da identidade timorense. Assim, seu corpus era alto (75) em relação ao seu status que era baixo (14), que basicamente era usado em alguns 
momentos no colégio, possuindo também alguns documentos escritos a fim de catequização.

A fig.1 abaixo explicita a relação entre o português e o Tétum-Praça, com o português apresentando um status alto e corpus baixo, e o Tétum um corpus alto e um status baixo, características típicas de contextos coloniais ou pós-coloniais, onde a língua do colonizador é valorizada, mas pouco falada, enquanto as línguas nativas são faladas por maior parte da população, porém não são valorizadas:

Figura1: Grade do português e Tétum em Timor Português

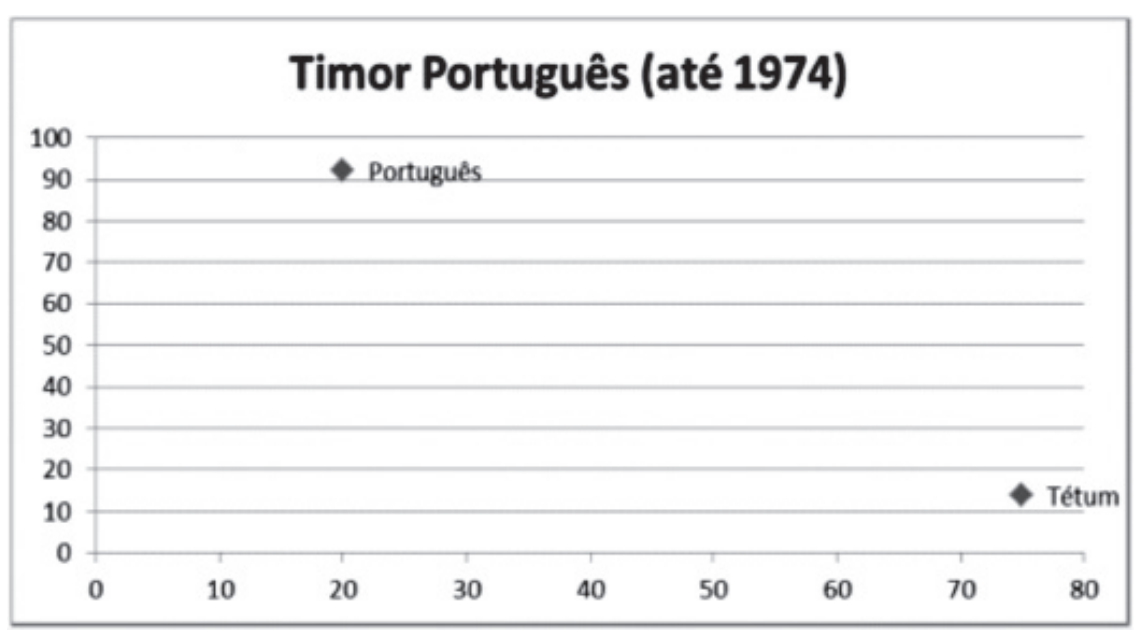

\subsection{O período indonésio}

O período indonésio iniciou-se em 1975 quando a indonésia invadiu Timor e o anexou como $27^{a}$ província. Durante este período, a Indonésia procurou estabelecer uma dominação efetiva, para tanto optou por implantar seu sistema educacional, retirando de maneira violenta todas as influências portuguesas (a língua, o ensino, a religião católica e outros aspectos culturais) e, paulatinamente, retirou também a língua Tétum do sistema educacional, já que a língua representava um símbolo de identidade histórica, nacional e grupal, podendo ser usada como uma ferramenta de resistência.

A língua usada na nova administração, no ensino e em todas outras esferas sociais passou a ser o indonésio. Segundo dados de Arenas (1998), a Indonésia construiu cerca de 1000 escolas, aumentou a taxa de escolarização para $75 \%$ e possuía 200.000 alunos timorenses matriculados, além disso, havia um fluxo constante de professores indonésios capacitados, chegando a ser mais da metade dos mais de 10.000 professores em exercício em Timor. De acordo com os dados apresentados, percebe-se que a Indonésia acabou por realizar um processo eficaz de introdução do indonésio, o que prejudicou tanto o status quanto o corpus do português e do Tétum-Praça, já que ambos não possuíam espaço no planejamento linguístico da Indonésia. 
Assim, o corpus do Tétum reduziu ligeiramente, 68 (fig. 2) em comparação com os 75 anteriores (fig. 1), por deixar de ser falado por uma parcela da população, porém de maneira contraditória o status do Tétum subiu um pouco, de 14 para 20, pois apesar de perder certos atributos do status, como o ensino, a língua ganhou importância nos movimentos nacionalistas de resistência (língua grupal, de identidade e de resistência), sendo usada pela igreja católica (língua de religião) e foi uma língua estudada em universidades indonésias por ser falada também em território indonésio, no lado oeste da ilha. Essas modificações se encontram abaixo na fig.2:

Figura 2: Grade do português e Tétum-Praça no período indonésio

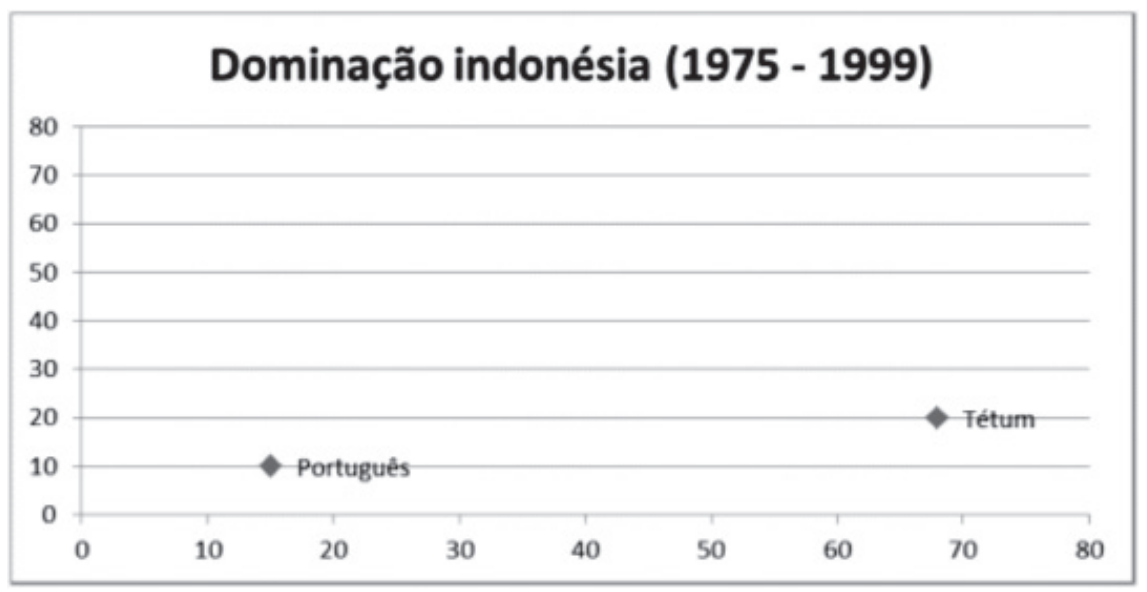

\subsection{O período atual}

Em 2002, Timor tornou-se independente, sob o nome de República Democrática de Timor-Leste, e sua constituição considera o português e o Tétum-Praça línguas oficiais. Assim, o desequilíbrio de status e corpus, causado por ações específicas durante o período indonésio, tentou ser reestabelecido pela política linguística explícita na constituição, assim como com novas ações no plano do planejamento linguístico.

Ainda, neste período, o meio ambiente linguístico leste-timorense sofreu a inserção de mais outro fator de peso, a língua inglesa, que foi inserida durante os anos de administração provisória (1999-2002), principalmente via funcionários da ONU, eque se mantém até os dias atuais. Além disso, como já foi apresentado, houve a inserção do português e do indonésio, dois elementos que causaram desequilíbrio, deixando marcas na ecologia linguística de Timor-Leste.

As modificações principais em relação ao Tétum-Praça, conforme foi analisado em (2), foram duas: um planejamento linguístico in vitro para aumentar o status da língua e o aumento do corpus, que ocorreu in vivo. O planejamento para aumentar a im- 
portância do status do Tétum-Praça foi o conjunto de medidas que tornaram a língua oficial, nacional, de ensino, da administração, com ortografia oficial, usada nos setores secundários e terciários, assim como em meios de comunicação em massa, principalmente rádio e TV. Em relação ao corpus, o Tétum-Praça retomou sua importância cultural e nacional, continuando a ser empregada como língua veicular entre os diversos grupos etnolinguísticos do país.

A língua portuguesa também retomou seu status, ao ser considerada língua oficial, de ensino, da administração, entre outros. Porém, o português perdeu certos atributos para o Tétum, como a língua de religião, além de não ser mais a única língua utilizada nos diferentes espaços sociais, já que atualmente o português está competindo com o inglês e o indonésio em alguns órgãos governamentais, nos meios de comunicação em massa (principalmente internet, jornais impressos e livros), e nas escolas e universidade. Ainda, no âmbito oficial o português está competindo constantemente com o Tétum-Praça.

A fig.3 resume as informações apresentadas acima. O status do português (72) acaba por se aproximar do Tétum (65), o que é um sinal de um bom planejamento linguístico, que valoriza a língua nativa, dispondo de um status mais equilibrado com seu corpus, no caso do Tétum, o corpus continua sendo elevado (90). Já o corpus do português, mesmo seguindo censos recentes, continua sendo reduzido (15), por ser falado por uma pequena parcela da população, não ser língua materna de nenhum leste-timorense e não possuir nenhuma função veicular.

Figura 3: Grade do português e Tétum-Praça em Timor-Leste

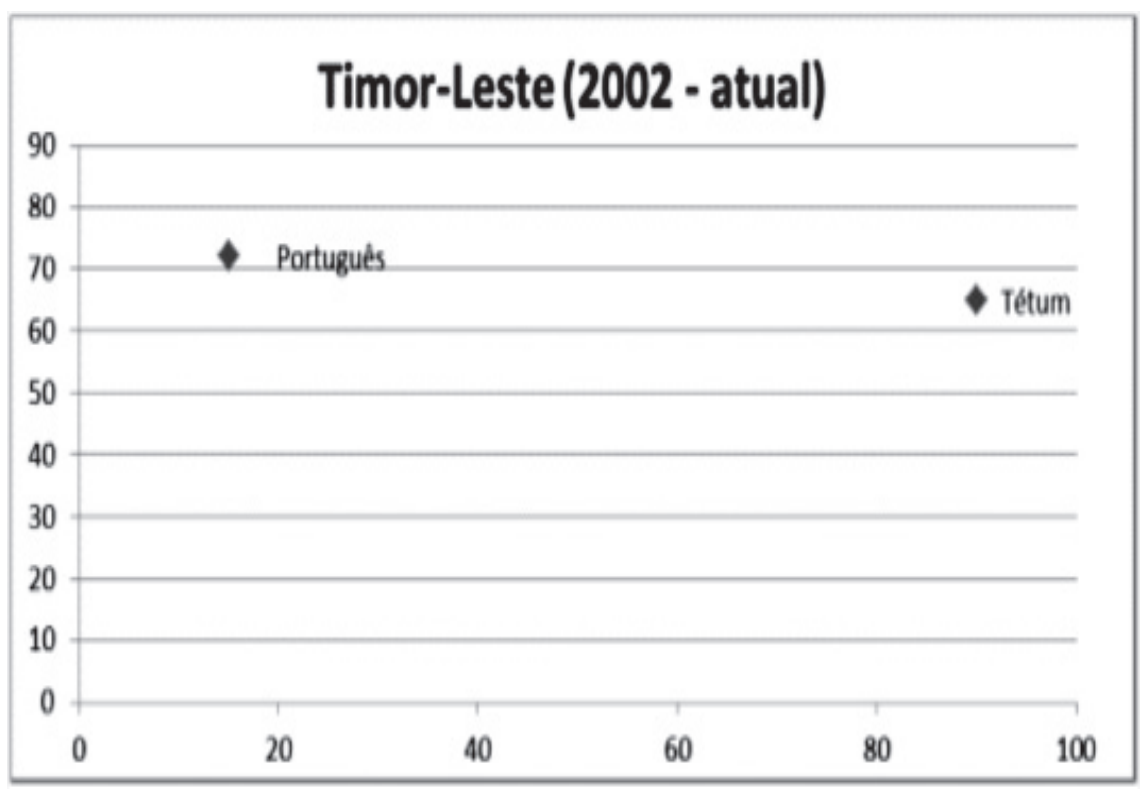




\section{Considerações finais}

O presente trabalho analisou política e planejamento linguísticos em Timor Leste, enfatizando as línguas oficiais, a saber: o português e o Tétum-Praça. Descreveu-se a situação atual de cada língua oficial no país. Na seção (2), foram analisados o corpus e o status da língua Tétum, assim como situações in vivo e in vitro que os modificaram de alguma forma. Na seção (3), uma análise semelhante foi feita para a língua portuguesa, excetuando, porém, que o status do português, como a língua do colonizador, mantevese alto e o planejamento linguístico objetivou principalmente aumentar o corpus.

Neste artigo, elaboraram-se também grades de análise, em (4), comparando o status e o corpus do português e do Tétum-Praça em diferentes momentos da história do país, que apresentaram diferentes políticas e planejamentos linguísticos. Essas grades visam resumir todas as informações apresentadas no decorrer do artigo, assim como atribuir valores numéricos, seguindo a proposta de Chaudenson (2004), para ser medida a situação de cada língua no âmbito do planejamento linguístico aplicado no país.

No período de Timor Português (até 1974), o país apresentou um planejamento típico de situação colonial da língua portuguesa (língua do colonizador) com status alto e corpus baixo, enquanto o Tétum-Praça e as demais línguas nativas possuíam um status menor e um corpus maior. Tal situação foi modificada durante a dominação indonésia (1975-1999), que desestabilizou a ecologia linguística do país, tanto para o português quanto o Tétum-Praça sendo desconsiderados no planejamento linguístico. Finalmente, a partir de 2002 até os dias atuais, o planejamento linguístico vem se destacando pela tentativa de equilibrar o valor do status entre português e Tétum-Praça, procurando valorizar e manter a língua Tétum em diversas situações sociais. Porém, o que aconteceu na realidade é que a língua portuguesa acabou por perder status e corpus. Todavia, não foi a língua Tétum que preencheu o hiato deixado pelo português, mas as línguas de trabalho, o inglês e o indonésio.

Logo, é possível afirmar que a vantagem do planejamento linguístico atual foi valorizar o status do Tétum-Praça, assim como manter a importância do corpus. Porém, as desvantagens foram várias, entre elas: a língua portuguesa perdeu grande parte de seu status durante a dominação indonésia e recuperou somente uma pequena parte deste, da mesma maneira seu corpus continua a ser reduzido; outras línguas estrangeiras acabam por adquirir importância, como o inglês e o indonésio, e retirar espaços sociais da língua portuguesa, do Tétum-Praça e das demais línguas nativas; apesar de os documentos oficiais versarem sobre a proteção e manutenção das línguas nativas, nada é feito no nível do planejamento linguístico $\stackrel{1 s}{\text {. }}$ 
Assim, em tempos próximos esses problemas têm que ser discutidos e avaliados, pois, caso o meio ambiente linguístico de Timor-Leste permaneça dessa maneira, poderá ameaçar a sobrevivência e a manutenção da língua portuguesa e das muitas línguas nativas do país.

\begin{abstract}
This paper intends to analyze language policy and language planning for Portuguese and Tétum-Praça in Timor-Leste in view of the fact that both languages are guaranteed as official languages in the 2002 National Constitution. Hence, in (2), corpus and status planning for Tétum-Praça will be discussed, followed by the examination of the higher status that Portuguese language presents in the country, in (3). Finally, in (4), analytical grids will be elaborated to evaluate the effects of language planning in various periods in East Timorese history.
\end{abstract}

Keywords: language policy; language planning; official languages; East Timor; Portuguese language.

\title{
REFERÊNCIAS
}

ALBUQUERQUE, Davi B. Pré-história, história e contato linguístico em Timor Leste. In: Domínios de Lingu@gem, v. 6, n. 2, p. 75-93, 2009. ARENAS, Alberto. Education and Nationalism in East Timor. In: Social Justice, v. 25, n. 2, p. 131-148, 1998.

BLANCHET, Philippe. Linguistique de terrain: Méthode et théorie. Rennes: Presses universitaires de Rennes, 2000.

BOXER, Charles R. The Topasses of Timor. Amsterdam: Indisch Instituut, 1947.

BOYER, Henri. Sociolinguistique: Territoire et objets. Lausanne: Delachoux et Niestlé, 1996.

CALVET, Louis-Jean. Sociolinguistique. Paris: Presses universitaires de France, 1993.

. Les politiques linguistiques. Paris: Presses universitaires de France, 1996.

. In vivo vs. in vitro. In: MOREAU, Marie-Louise. (ed.). Sociolinguistique. Concepts de base. Sprimont: Mardaga, p. 179-180, 1997.

CASTRO, Alberto O. A ilha verde e vermelha de Timor. Lisboa: Edições Cotovia, 1996 [1943]. 
CHAUDENSON, Robert. La francophonie: représentations, réalités et perspectives. Aix-en-Provence: Institut d'études créoles et francophones de l'université de Provence, 1991.

. Grille d'analyse des situations linguistiques. Paris: Agence Universitaire de la Francophonie, 2004.

CORDEIRO, Luciano. Questões Coloniais I. Documenta Historica 6. Lisboa: Editorial Vega, s.d.

COSTA, Leão. A luta pela preservação da identidade cultural timorense no tempo da ocupação. Studies of Language and Cultures of East Timor, v.5, p. 11-17, 2002/2003.

FASOLD, Ralph. The Sociolinguistics of Society. Londres: Blackwell, 1984.

FIGUEIREDO, Fernando A. Timor. A presença portuguesa (17691954). Tese (Doutorado). Faculdade de Letras, Universidade do Porto, Porto. 2004.

FOX, James J. Tracing the path, recounting the path: historical perspectives on Timor. In: FOX, James J; SOARES, Dionisio B. (eds.) Out of the ashes: destruction and reconstruction of East Timor. Hindmarsh: Crawford House Publishing, 2000.

HAJEK, John. Language planning and the sociolinguistic environment of East Timor: colonial practices and changing language ecologies. Current Issues in Language Planning, v. 1, p. 400-413, 2000. HULL, G. A Morphological overview of the Timoric Sprachbund. Studies in Languages and Cultures of East Timor, v.4, p. 98-205, 2001. INSTITUTO NACIONAL DE LINGUÍSTICA (INL). Hakerek Tetun tuir Banati, Kursu Ortografia Patronizada nian. Dili: Instituto Nacional de Linguística, Universidade Nacional Timor Lorosa'e, 2002. . Matadalan Ortográfiku ba Tetun-Prasa.Dili: Instituto Nacional de Linguística, Universidade Nacional Timor Lorosa'e, 2003.

KLOSS, Heinz. Research possibilities on group bilingualism: a report. Québec: Centre International de Recherche sur le Bilinguisme, 1969.

MARCOS, Artur. Timor Timorense. Com suas línguas, literatura, lusofonia. Lisboa: Colibri, 1995.

NATIONAL BOARD OF STATISTICS. Timor-Leste Census of Population and Housing 2004. Priority Tables Editions: National Board of Statistics and the United Nation Fund for Population, 2006.

PROGRAMA DAS NAÇÕES UNIDAS PARA O DESENVOLVIMENTO. Relatório do Desenvolvimento Humano de Timor Leste. Dili: UN Agency House, 2002.

REPÚBLICA DEMOCRÁTICA DE TIMOR-LESTE. Constituição da República Democrática de Timor-Leste. Dili, 2002. Disponível em: http://timor-leste.gov.tl/wp-content/uploads/2010/03/Constituicao_RDTL_PT.pdf. Acesso em: 21 nov. 2010. 
REPÚBLICA DEMOCRÁTICA DE TIMOR-LESTE. Decreto do Governo $\mathrm{n}^{\circ}$. 1, 2004. O padrão ortográfico da língua Tétum. Dili, 2004. Disponível em:

http://www.jornal.gov.tl/public/docs/2002_2005/decreto_governo/1_2004.pdf. Acesso em: 22 de nov. 2010.

SÁ, Artur B. Textos em teto da literatura oral timorense. Lisboa: Junta de Investigações

do Ultramar, 1961.

TAYLOR-LEECH, Kerry. The ecology of language planning in Timor-Leste. Development Bulletin, n. 63, p.116-120, 2005.

The ecology of language planning in Timor-Leste: A study of language policy, planning and practices in identity construction. Tese (Doutorado). Griffith University, Queensland, Australia. 2007. . The language situation in Timor-Leste. Current Issues in Language Planning, v.10, n.1, p.1-68, 2009.

THOMAZ, Luis F. De Ceuta a Timor. Carnaxide: Difel, 1994. Babel Loro Sa'e: O Problema Lingüístico de Timor Leste.

Lisboa: Instituto Camões, 2002. 